\title{
Por uma atenção do cuidado de si na escola em tempos de dispersão hiperconectada
}

\author{
Maria Alice Gouvêa Campesato \\ Betina Schuler \\ Universidade do Vale do Rio dos Sinos (Brasil)
}

\section{Resumo}

No deslocamento de uma sociedade disciplinar para uma de controle com características de super desempenho, aceleração e concorrência, este artigo problematiza o conceito da atenção em suas implicações com a educação. Este conceito ganha força na modernidade e, mais contemporaneamente, é operado como déficit e como importante valor de mercado. Este ensaio, cuja fundamentação teórico-metodológica dialoga com o pensamento de Michel Foucault, realiza uma revisão bibliográfica analítica sobre a temática da atenção, buscando diagnosticar o que estamos nos tornando no presente, quando as escolas são acusadas de não mais conseguirem manter a atenção dos alunos. Avolumam-se, então, práticas pedagógicas inovadoras, sugerindo estratégias de marketing e entretenimento. Todavia, questionamos o quanto essas mesmas práticas também produzem uma dispersão hiperconectada. Como modo de combate ético e político, optamos por perguntar pela atenção implicada nas práticas educativas a partir do conceito de cuidado de si em Foucault, atravessado por certa conversão do olhar.

Palavras-chave: Atenção. Educação. Inovação. Cuidado.

\section{For attention to the care of the self at school in times of hyperconnected dispersion}

\begin{abstract}
In the shift from a disciplinary society to a control society with characteristics of super performance, acceleration and competition, this paper problematizes the concept of attention in its implications in education. This concept has gained strength in modernity and, contemporaneously, has functioned as a deficit and as an important market value. This essay, whose theoretical and methodological foundation dialogues with the thought of Michel Foucault, performs an analytical and bibliographical review on the theme of attention, seeking to diagnose what we are becoming in the present, when schools are accused of not being able to keep students' attention. Innovative pedagogical practices are thus increasing, suggesting marketing and entertainment strategies. However, we question how much these same practices also produce a hyperconnected dispersion. As a way of ethical and political combat, we chose to ask for the attention involved in educational practices from the concept of self-care in Foucault, crossed by a certain conversion of the look.
\end{abstract}

Keywords: Attention. Education. Innovation. Care. 


\section{Por una atención del cuidado de sí en la escuela en tiempos de dis- persión hiperconectada}

\section{Resumen}

En el cambio de una sociedad disciplinar para una sociedad de control con características de súper desempeño, aceleración y competencia, este articulo problematiza el concepto de la atención en sus implicaciones con la educación. Este concepto gana fuerza en la modernidad y, más contemporáneamente, se opera como déficit y como un importante valor de mercado. Este ensayo, cuya base teórica y metodológica dialoga con el pensamiento de Michel Foucault, realiza una revisión bibliográfica analítica sobre el tema de la atención, buscando diagnosticar en qué nos estamos convirtiéndonos en el presente, cuando las escuelas son acusadas de no poder mantener la atención de los alumnos. Las prácticas pedagógicas crecen, sugiriendo estrategias de marketing y de entretenimiento. como forma de agradar, ahora, a los alumnos-clientes. Sin embargo, cuestionamos cuánto estas mismas prácticas también producen una dispersión hiperconectada. Como modo de combate ético y político, elegimos pedir la atención involucrada en las prácticas educativas a partir del concepto del cuidado de sí en Foucault, atravesado por una cierta conversión de la mirada.

Palabras clave: Atención. Educación. Innovación. Cuidado. \\ Cenas Introdutórias: a discursividade no contemporâneo}

Há um regime discursivo na atualidade que insiste em colocar a escola em uma posição de obsolescência. A discursividade em voga argui que os alunos "[...] nascidos no século XXI, tendo aula com professores formados no século XX em uma escola que em muito se assemelha às escolas do século XIX" (DESCHAMPS; CALEGARI, 2015, p. 7), parece não deixar dúvidas sobre o desalinho entre a referida instituição e as demandas contemporâneas. $\mathrm{Na}$ mídia, em especial, fulguram enunciados, ora salvacionistas, ora reformadores, que, por um lado, se investem contrários ao que se ensina e à maneira como isso é feito, e, por outro, defendem os "interesses e necessidades do alunado", apontando um "descompasso" entre ambos (VAL; AQUINO, 2013, p. 1 1). Dessa feita, ocorre um encorajamento para que a escola, articulada a outras esferas [...] produza a reelaboração de currículos, métodos e posturas docentes. Tratam-se de enunciados que oferecem um conjunto prescritivo de procedimentos a fim de que a escola ultrapasse o estágio em que se encontra".

Os enunciados que colocam a escola em defasagem em face das emergências contemporâneas tornaram-se uma doxa: assim como os gregos 
no tempo de Platão eram, segundo Gallo (2008, p. 63), "[...[ dominados pela doxa, pelas aparências sensíveis, e só a Filosofia poderia mostrar o verdadeiro mundo, também nós, dominados pelas mídias e pela literatura best-seller estamos condenados às opiniões e às fáceis certezas[...]" dos que se autoproclamam experts nos assuntos educacionais. As opiniões e fáceis certezas deslizam em um cenário propício à fragmentação de ideias, frases curtas e manchetes impactantes que disputam a atenção do consumidor. Uma direção que conduz a um veredito: morte à escola e à aula.

Alguns, menos enfáticos, propõem a adequação, transformando a aula em centro de conexões, colocando os alunos em movimento constante para que não se entediem. Nessa lógica, procura-se competir pela atenção dos alunos, buscando, nas estratégias de marketing, o arbítrio do ensinar contemporâneo, que persegue o prazer imediato, o interesse, a utilidade pragmática e a medição de toda a produção feita. Trata-se, pois, de uma linguagem instrumental que vem sendo assumida em nome do progresso e da eficiência, em que quase nada dura o suficiente para que se tenha intimidade com o pensamento. Assim, a finalidade da escola não é mais discutida quando as metodologias para a manutenção da atenção do aluno se colocam na centralidade.

A aposta que busca reformular a escola encontra terreno profícuo na inovação, apontada como uma solução importante para enfrentar os problemas educacionais da atualidade, seja na formação docente, nas políticas públicas, nas mudanças curriculares ou nos modos de avaliação, em que o aprender a aprender e a individualidade são muito mais valorizados do que o ensino e o trabalho coletivo, devendo voltar-se para a inovação ICOSTA, 2009). Bastante utilizada em diversos setores da economia e da administração, a palavra "inovação" tem sido incorporada ao léxico educacional.

Conforme o Manual de Oslo: Diretrizes para coleta e interpretação de dados sobre inovação, produzido pela Organização para a Cooperação e Desenvolvimento Econômico (OCDE, 2005, p. 43), a inovação "[...] requer a utilização de conhecimento novo ou um novo uso ou combinação para o conhecimento existente [...] requer esforços inovadores que podem ser distinguidos das rotinas padronizadas" (OCDE, 2005, p. 43).

Ao deslocarmos tal conceptualização para o campo educacional, podemos perceber a produção de modos de subjetivação no presente, 
Por uma atenção do cuidado de si na escola em tempos de dispersão hiperconectada

atravessados pela volumosa oferta de estímulos, produtos e informações, a partir de outras relações com o tempo e o espaço, o que vem a modificar drasticamente a "estrutura e economia da atenção" (HAN, 2017, p. 31).

Conceituada de diversas maneiras ao longo dos séculos, a atenção vem se modificando, produzida por diferentes relações de forças em luta. Decorre daí a afirmação de Caliman (2008) de que a atenção é um conceito nômade e estratégico. Isso nos auxilia a compreender como ela vem sendo percebida na contemporaneidade: pela sua falta e, ao mesmo tempo, como um "valor" (CALIMAN, 2008). A falta evidencia-se nas síndromes de transtornos de déficit de atenção; o valor, na economia da atenção.

Na atualidade, a atenção desloca-se permanentemente, "transparecendo uma certa dificuldade de concentração. Numa busca acelerada de novidade, a atenção é passageira, muda constantemente de foco e é sujeita ao esgotamento em frações de segundos (KASTRUP, 2004), provocando uma intensa dispersão. Porém, essa dispersão percebida na contemporaneidade torna-se um problema imperativo já no final do século XIX (CRARY, 2013), em que uma série de estímulos promovem a modificação no campo perceptivo. Com o advento da internet no século XX, tais estímulos multiplicam-se vertiginosamente, potencializando essa dispersão hiperconectada.

No âmbito educacional, a atenção é frequentemente acompanhada de sua antonímia, em que o déficit é um fator explicativo para a não aprendizagem, sendo percebida pelo seu aspecto funcional. Nas instituições escolares, o número de crianças e adolescentes com diagnósticos de TDAH vem aumentando significativamente, assim como os discursos docentes sobre a dificuldade em manter a atenção dos alunos nas aulas. Por outro lado, percebe-se que as próprias práticas pedagógicas contribuem para potencializar tal dispersão, visto que promovem atividades variadas, dinâmicas, de curto período, com o propósito de manter o interesse e a atenção dos alunos. Talvez esse paradoxo que se dá no campo educacional venha a explicar a convergência dos estudos sobre a atenção pela sua falta, conforme aponta a revisão bibliográfica

'realizada: há uma gama de pesquisas voltadas para os transtornos de déficit de atenção articulados à hiperatividade e a problemas de aprendizagem e de comportamento. Os estudos acerca da atenção como um fenômeno concentram-se, em sua grande maioria, nas áreas de psicologia e de medicina social. 
Trazer, portanto, a atenção para o centro do debate educacional, desvinculada dos déficits e transtornos, pode auxiliar-nos a compreender as relações que se estabelecem no âmbito escolar na atualidade. Se a instituição escola tem se mostrado "ineficaz e apartada das novas gerações", conforme advoga o regime de verdade contemporâneo, torna-se crucial, antes de pensarmos em propostas que venham a incrementar um currículo pauperizado, exaurido e obsoleto no mundo acelerado, cogitarmos problematizar a atenção e a escola a partir de outras perspectivas.

Partimos, então, de uma pesquisa bibliográfica com inspiração arquegenealógica baseada nos estudos de Michel Foucault (2004, 2005, 2008, 2014,2017 l para olharmos a constituição histórica dos saberes sobre a atenção e a escola como mais um saber, que se combina a tantos outros, instituindo verdades e efeitos específicos de poder. Desse modo, é possível problematizar como podemos ser tomados no presente como objeto de conhecimento em relação à atenção, ao interesse e à inovação no campo educacional e, ao mesmo tempo, sermos subjetivados como sujeitos desatentos. Não se trata da validação e cientificidade do conhecimento, da verificação da oposição de verdade e erro, sendo a ciência o princípio de julgamento, pretendendo determinar a legitimidade dos conhecimentos e subordinando a verdade à ciência, pois a ciência é colocada no lugar de verdade, uma vez que seus procedimentos a garantiriam (MACHADO, 2006). Esta pesquisa entende que a verdade é mais um valor, uma configuração histórica, e o que importa são as condições de existência, e não de validade.

Este tipo de análise busca o que aparentemente é banal para ser problematizado, fazendo aparecer uma rede de microrrelações de poder, no sentido de que aquilo que faz com que tantas coisas ditas há tanto tempo não tenham surgido segundo leis de pensamento, de um sujeito fundante, mas que tenham se constituído devido a uma rede de relações que caracterizam o nível do discurso, de acordo com suas possibilidades e impossibilidades enunciativas, não havendo enunciado livre, independente, pois fará sempre parte de um conjunto. Assim, não se trata de desvendar uma verdade metafísica de um sentido, buscar uma essência, mas de mostrar as estratégias de produção dos efeitos de verdade em práticas que obedecem a determinados tipos de racionalidade e que produzem determinadas formas de ser em exercícios de poder. A partir disso, buscamos pensar em como podemos exercer uma relação mais ética conosco mesmos e com os demais, como uma prática estética 
Por uma atenção do cuidado de si na escola em tempos de dispersão hiperconectada

de resistência em tempos de práticas pedagógicas inovadoras que nos tomam como médias quadriculadas na produção de sujeitos autoempreendedores.

\section{A atenção na escola: de um problema marginal a um valor de mercado na produção do sujeito empreendedor de si}

Conforme apontado, a atenção vem sendo percebida e conceituada de diversas formas no decorrer da história humana, tornando-se um problema crucial desde a Modernidade. $\bigcirc$ teórico da arte moderna, Jonathan Crary (2013, p. 29) na obra Suspensões da percepção: atenção, espetáculo e cultura moderna, examinou como a atenção constituiu-se em um problema novo no século XIX, sendo concebida de maneira diversa da que se tinha até então e tornando-se "[...] inseparável das investigações filosóficas, psicológicas e estéticas acerca da percepção". Nesse estudo, Crary (2013, p. 40) argumenta que a atenção era um conceito marginal, cuja importância era "[...] apenas local e em assuntos ligados a educação, cultivo pessoal, práticas pedagógicas e mnemônicas ou investigações científicas". E é mais precisamente a partir dos anos de 1870 que a atenção passa a ser compreendida como um problema que atinge um espectro social mais amplo.

Nossas pesquisas apontam que a problemática da atenção já se fazia presente na Antiguidade e no Medievo: Aristóteles (1991, p. 233), no século IV a.C., na Ética a Nicômaco, diz que é a novidade das coisas que as tornam aprazíveis, mas "[...] menos quando deixam de sê-lo, e por esse mesmo motivo: a princípio a mente é estimulada e desenvolve intensa atividade em relação a elas, como fazemos com o sentido da vista quando olhamos alguma coisa com atenção". No ano 426 de nossa era, Agostinho (2000, p. 1038) declara, em Civitate Dei, que a atenção de Deus "[... não passa de um pensamento para outro pensamento, mas ao seu olhar incorpóreo, tudo o que sabe está simultaneamente presente".

Porém, é importante lembrar que a sistematização dos estudos sobre a atenção só ocorrerá na Modernidade. Embora no pensamento moderno haja uma retomada das obras ditas clássicas da Antiguidade greco-romana, ela se deu sob as lentes de um novo homem. Houve uma "releitura" do pensamento antigo, adaptado ao emergente mundo organizado, sistematizado, científico, disciplinar e de base escolar que se constituía. 
$\bigcirc$ interesse pela atenção vem associado à aceleração da vida moderna, podendo ser compreendido sob dois aspectos complementares e não excludentes: a sofisticação da maquinaria capitalista e a mudança dos meios perceptivos. A partir do final do século XIX e, de forma acentuada, nas últimas décadas do século XX, o mundo capitalista produziu uma gradativa reformulação da "experiência sensorial" (CRARY, 2013, p. 35), em que, o que "[...] costumamos chamar de cinema, fotografia e televisão são elementos transitórios em uma sequência acelerada de deslocamentos e obsolescências que são parte das operações delirantes da modernização". Pode-se dizer, então, que as experiências sensório-motoras provocam mudanças significativas com relação ao corpo.

Desse modo, podemos pensar que a centralidade no problema da atenção estava relacionada à saturação de informações sensoriais. "A desatenção, em especial no contexto das novas formas de produção industrial em grande escala, começou a ser tratada como um perigo e um problema sério" (CRARY, 2013, p. 36), apesar de a modernização do trabalho ser responsável pela produção dessa desatenção. Os procedimentos na produção fabril exigiam atenção cada vez maior dos trabalhadores para evitar acidentes no manejo das máquinas e equipamentos e manter o ritmo da produção, levando a atenção a ser compreendida como uma questão de saúde e econômica.

No campo educacional desse período, a pedagogia alcança o status de ciência, que num único golpe, não somente põe em xeque os "métodos autoritários da escola 'tradicional' - que via todos os estudantes da classe como um só e se limitava ao básico 'ler, escrever e contar'", mas também busca a formação "integral' do indivíduo, tomado em si e para si". (Ó, 2009, p. 1 14, grifo das autoras). É nesse contexto da emergência de uma psicologia experimental no século XIX e início do século XX, com autores como Herbart, Claparède e Decroly, por exemplo, que se solidifica a ideia de que somente teremos crianças atentas na escola se estivermos dando conta de seus interesses individuais e de que a escola deve ser ativa, operando por meio de atividades espontâneas e produtivas (Ó, 2003). Esse é um enunciado que se fortalece no Brasil com o Movimento da Escola Nova, no início do século $X X$, e que, no presente, é capturado por uma lógica neoliberal, com todo o seu léxico empresarial, que invade as escolas para explicar como as crianças aprendem ou como deveriam aprender no século XXI. 
Por uma atenção do cuidado de si na escola em tempos de dispersão hiperconectada

Todo esse empreendimento, por um lado, procura compreender o funcionamento dos fenômenos do corpo e da mente, por outro, busca exercer sobre eles uma espécie de poder, que se torna extremamente eficiente quando funciona como autodisciplina (FOUCAULT, 2004). $\bigcirc$ corpo, cada vez mais, passa a ser investigado em suas minúcias e detalhamentos, virado ao avesso, escaneado e, ao mesmo tempo, compreendido como elemento-chave da economia e regulado como população, a partir de uma específica economia da atenção.

As instituições disciplinares, paulatina e minuciosamente desde 0 século XVIII, desenvolverão técnicas de controle sobre os corpos e suas relações no espaço e no tempo. A escola e a aula constituem-se como os espaços formativos de domesticação do corpo e da alma, onde se engendra uma gama de técnicas, dispositivos e procedimentos que buscam, a um só tempo, disciplinar os saberes e o corpo, tornando-o útil economicamente e submisso politicamente. $\bigcirc$ espaço educacional é, pois, atravessado por uma enorme vontade de saber, gestado a partir de uma vigilância hierarquizada, de uma sanção normalizadora e do exame, que coloca o sujeito em uma lógica escrita e documental. A tecnologia que acompanha o exame transforma o indivíduo 8 em um caso a ser estudado e conhecido, para si e para os demais (FOUCAULT, 2004).

A partir da segunda metade dos 1700, surge uma nova tecnologia, diversa da disciplinar, que não the é excludente, mas a agrega, dirigindo-se ao "ao homem-espécie", ou à biopolítica, direcionada à massa global, em que aspectos como nascimento, morte, doença, etc. se tornam o centro de atenção desse poder massificante (FOUCAULT, 2005).

corpo, então, no século XIX, passará a ser compreendido, por grande parte das teorias fisiológicas e psicológicas, como o responsável pelo controle dos impulsos, e a atenção é um dos mecanismos responsáveis "[...] pela adaptação da ação humana ao mundo físico, político e social da época" (CALIMAN, 2008, p. 64 1). A maquinaria escolar moderna pode ser pensada em sua montagem focada na preocupação com a concentração das crianças, desenrolando-se aí todo um governo da atenção infantil. Desse modo, "[...] a partir de então, o corpo atentivo esteve na base dos projetos sociais e estéticos de normatização e de liberação da subjetividade" (CALIMAN, 2008, p. 641). 
Além da concordância entre estudiosos do tema acerca da fenomenologia mínima da atenção, é consensual a ideia de que foi no século XIX que a atenção ganhou relevância, ou "[...] corpos: o corpo cerebral, o corpo neurofisiológico, sensorial e motor, o corpo relacional, social estético e emocional" (CALIMAN, 2006, p. 12), sendo que o neurofisiológico recebeu destaque dentre os demais, repercutindo, no campo educacional, nas teorias pedagógicas do ensino, da aprendizagem e das práticas nas salas de aulas. Nesse contexto de elogio à psicometria, no final do século XIX e início do XX, a "Educação Nova [...] alicerça-se no conhecimento detalhado da diferença de cada criança. Fala mesmo da 'lei da individualidade', querendo por tal significar que todo o indivíduo" (Ó, 2009, p. 114-1 15, grifo das autoras) apresenta características físicas e psicológicas que o diferenciam dos demais. Não podemos, porém, fazer aproximações apressadas entre a cerebrização e a Escola Nova, pois o que tentamos entender são as regularidades e deslocamentos no campo educacional.

Na última década do século XX, deu-se um incremento nas pesquisas neurocientíficas, e "[...] o cérebro tem recebido considerado destaque entre os agentes biológicos supostamente determinantes de transtornos mentais e comportamentos" (ZORZANELLl; ORTEGA, 201 1 , p. 13). Conforme Alain Ehrenberg (2009), o conjunto de disciplinas organizadas sob o rótulo de neurociências se dedicava, tradicionalmente, ao estudo do movimento, dos sentidos, da aprendizagem, das doenças neurológicas e patologias mentais. Porém, a partir da década de 1980, ocorrem duas mudanças: a primeira é que as doenças neurológicas e as doenças mentais passaram a ser tratadas como uma única, e a segunda é que se ampliou o espectro de investigação daquelas disciplinas, incorporando ao seu campo o estudo sobre "[...] emoções, comportamentos sociais e os sentimentos morais" (EHRENBERG, 2009, p. 188).

Assim, a possibilidade de ver o corpo por dentro apresenta-se como um novo paradigma aos sujeitos modernos. Quando o físico alemão W. Roentgen, em 1895, produziu radiação eletromagnética, as "[...] imagens de raios $X$ contribuíram para apagar distinções sociais e morais, e a própria ideia de privacidade e intimidade começou a mudar [...]" (ORTEGA, 2006, p. 91) na sóbria sociedade vitoriana. Pouco mais de um século desde esse episódio, vivemos em uma exposição constante nas redes sociais - de vísceras, ossos, sangue ou nossos pensamentos mais íntimos. Trata-se de uma cultura em que a intimidade se apartou da proteção, tornando-se exposta, conforme Ortega 
Por uma atenção do cuidado de si na escola em tempos de dispersão hiperconectada

(2006, p. 91), "[...] nos mais ínfimos detalhes em reality shows, programas de auditório, diários na Internet e outros teatros do eu contemporâneos, a interioridade visceral revelada pelas novas imagens acompanha esse processo de externalização". Uma externalização com a qual estamos nos acostumando quando pensamos nesses dispositivos de uma sociedade de controle (DELEUZE, 2008). Um fascínio que, para Sibilia (2008, p. 263), é "[...] suscitado pelo exibicionismo e pelo voyeurismo [e] encontra terreno fértil em uma sociedade atomizada por um individualismo com beiradas narcisistas, que precisa ver sua bela imagem refletida no olhar alheio para ser".

O corpo tornou-se, então, um objeto de espetacularização, e o cérebro passou a ocupar um lugar privilegiado. Segundo Silva e Vaz (2016, p. 216), a linguagem para abordar "[...] desejos, paixões, crenças, comportamentos, cognição e humor, deve ser expressa no registro do vocabulário cerebral, portanto, em termos de excesso ou falta de neurotransmissores e de patologias que afetam o cérebro". Ortega (2006, p. 91) dirá que o "[...] conhecimento do interior do corpo representa uma metáfora eficaz do conhecimento de si".

Juntamente com o enunciado que vincula atenção e falta, a partir de 10 uma perspectiva neurológica, podemos, no contemporâneo, também problematizar o quanto a atenção vem sendo tomada como um valor de mercado. Segundo o filósofo alemão Georg Franck (2002, p. 3, tradução livre), uma tendência à eficiência emerge quando a ciência é operada como "[...] uma economia em que os pesquisadores investem sua própria atenção, a fim de obter a atenção de outros. Vista assim, a comunicação científica parece ser um mercado onde a informação é substituída pela atenção".

No mundo empresarial contemporâneo, nesse capitalismo cognitivo e emocional, o interesse em torno da atenção volta-se para duas problemáticas: "[...] a autogestão da atenção e a atração da atenção do consumidor" (CALIMAN, 2012, p. 4). O sucesso do empresário está em saber selecionar, dentre uma multiplicidade de ofertas e possibilidades, o que é mais importante para transformar em ação, em que a atenção operaria como um "filtro seletivo", demandando habilidade e foco do gestor executivo. E essa perspectiva tem efeitos importantes no campo da educação.

Isso vai ao encontro dos desafios apontados por Sennett (2015) quando se refere ao "sujeito ideal" no mundo dos negócios no presente, pois 
todo aquele que deseja ser bem-sucedido deve lidar com as relações, com o talento e com o abandono do passado. Poderíamos aglutinar essas características em uma: flexibilidade. O sujeito flexível é aquele que consegue direcionar sua atenção para atingir um determinado propósito, fazendo as adequações necessárias para tal. Isso altera as formas de percepção e de atenção, pois, quando há mudança constante, não há um aprofundamento necessário para a perícia, uma vez que isso exige tempo; um tempo do qual as organizações e os indivíduos não dispõem: a perícia não é compatível com a flexibilidade (SENNETT, 20 15). Não obstante, "[...] as ineficiências e os desperdícios da atenção são vistos como irresponsabilidades não permitidas ou como deficiências que devem ser tratadas" (CALIMAN, 2012, p. 8).

Os problemas de atenção encontram-se nos diversos espaços sociais, em que o diagnóstico TDA é cada vez mais recorrente. Tal transtorno "[...] tem como sintomas baixo rendimento na realização de tarefas, dificuldade de seguir regras e desenvolver projetos de longo prazo, e cujo quadro pode estar associado à hiperatividade e à impulsividade" (KASTRUP, 2004, p. 7). Conforme De-Nardin e Sordi (2007, p. 1), o Diagnosticand Statistical Manual of Mental Disorders "[...] caracteriza esta patologia pela dificuldade em manter o foco de vigilância em tarefas". Analistas atribuem o problema da atenção à "[...] expansão da internet. Nas sociedades de informação, a disparidade entre a produção de conhecimento e sua codificação eficiente tornou-se patológica" (CALIMAN, 2012, p. 8). Fala-se, contemporaneamente, de patologias por excesso de informação, ou seja, desse sujeito esgotado do qual fala Han (2017).

Neste ponto, exige-se fazer uma parada e questionar: quais os efeitos que essa nova economia de uma atenção dispersa e hiperconectada tem na educação, quando o volume de informações é mais importante do que a problematização, quando é valorado o novo pelo novo em detrimento da tradição, quando quase nada dura o tempo suficiente para que se tenha intimidade com o pensamento? De que modos o campo educacional é atravessado por todos esses funcionamentos no presente?

Não buscando responder essas questões, mas pensando a partir delas, podemos colocar alguns enunciados que se entrecruzam, tais como a crise na escola e seu par perfeito, a inovação, a partir de uma linguagem instrumental que invade as escolas em nome do útil, do super desempenho, da realização pessoal e da satisfação e prazer imediatos. Assim, toma-se o aluno 
Por uma atenção do cuidado de si na escola em tempos de dispersão hiperconectada

como cliente, buscando-se reter sua atenção, agradar-the, para que possa desenvolver habilidades e competências para autogerir-se em um alto volume de informações, sendo que a habilidade principal seria a de conectar todas essas informações. A dedicação concentrada e atividades repetidas em uma lógica disciplinar (e aqui não há nenhum saudosismo) cedem espaço a atividades práticas, opiniáticas, rápidas, atrativas, individualizadas, passíveis de cálculo, úteis - e a aula transforma-se em um grande espetáculo para seduzir a frágil atenção dos alunos. A cultura letrada, dessa maneira, é retirada de um caráter salvacionista e civilizatório para ser operada com um tom instrumentalista de tipo empresarial, uma vez que se usam, por exemplo, a leitura e a escrita como "[...] ferramentas técnicas a serviço da navegação e conexão" (SIBILIA, 2012, p. 72). Desloca-se, pois, de uma escola disciplinar que buscava a formação do cidadão moralizado para uma subjetivação de tipo informacional que facilmente se entedia e se desconcentra, atravessada por inúmeros suportes, em que "[...] a opinião substitui o pensamento e a informação ocupa o lugar do saber ou do conhecimento" (SIBILIA, 2012, p. 86).

Daí que talvez não estejamos falando da atenção dos alunos, mas dá atenção de clientes e usuários da escola que operam de forma hiperacelerada; 12 tudo acontece tão rápido, que pouco fica de vestígio, de marcas. Esse funcionamento da atenção na escola está fortemente conectado com o que Han (2017) fala sobre a sociedade do desempenho, que nos pede superprodução; em que passamos a competir conosco mesmos; em que a atenção é destroçada em nome das atividades multitasking. Estando, então, no cruzamento de uma maquinaria sólida, em que valores disciplinares ofereciam a oportunidade futura, e uma maquinaria flexível, pautada pela lógica do mercado, parece não "[...] restar à escola outro remédio senão entrar no jogo como a única coisa que ela poderia ser: um produto entre inúmeros outros que deve competir para captar a atenção de seus clientes potenciais [...]" (SIBILIA, 2012, p. 66) se quiser manter-se no mercado.

A educação, a escola e a aula inserem-se, pois, nessa lógica concorrencial, produzindo modos de subjetivação proativos, flexíveis, competitivos - características essenciais para as políticas neoliberais contemporâneas, em que as "[...] pessoas não são (mais) tomadas como cidadãos sociais [...], mas entendidas como eus empresariais e empresários de si" (COSTA, 2009, p. 124). $\bigcirc$ sujeito empreendedor de si mesmo vê a si próprio como um investimento e, portanto, como um aprendiz por toda a vida; um sujeito que deve 
estar constantemente conectado às oportunidades para melhorar sua performance e concorrer, não somente com os outros, mas principalmente consigo mesmo, batendo as próprias metas. Por isso, a chamada da atenção do sujeito consumidor e a autogestão caminham de mãos dadas.

Isso é importante para compreendermos como, no campo educacional, a concepção utilitarista vem alicerçando as instituições escolares já desde o século XVI, em que o "[...] saber conheceu uma transformação maior quando foi, cada vez mais, visto como uma ferramenta capaz de 'resolver problemas "' (LAVAL, 2003, p. 7). $\bigcirc$ caráter utilitarista está presente nas diversas propostas pedagógicas das mais variadas tendências, desde aquelas que têm em sua base a tradição crítica até aquelas autoproclamadas inovadoras, que têm interesse em formar ou sujeitos críticos, capazes de competir no mercado de trabalho com condições de igualdade, ou sujeitos proativos, capazes de lidar com um mundo em constante mudança. A proatividade, o protagonismo, a flexibilidade e a capacidade de trabalhar em equipes partem da premissa de que os problemas são apresentados com o intuito de sua solução.

Podemos dizer que "[...] o homem benthamiano era o homem calculador do mercado e o homem produtivo das organizações industriais. $\bigcirc$ homem neoliberal é o homem competitivo, inteiramente imerso na competição mundial" (DARDOT; LAVAL, 2016, p. 322). A escola, pois, funciona como um dispositivo capital na constituição desse novo sujeito, e as práticas da atenção operam fortemente esse processo. Isso porque a falta de atenção se constitui como um dos grandes problemas educacionais da atualidade, e as ditas práticas pedagógicas inovadoras fulguram como a solução para tais problemáticas.

Vemos um movimento crescente em busca de soluções para os problemas educacionais em nível mundial. Tal movimento procura articular diversos setores da sociedade civil, em uma "[...] torrente de ideias reformadoras intimamente relacionadas entre si, está a possibilitar e a reorientar sistemas de educação com percursos e histórias muito diferentes, em situações sociais e políticas diversas" (BALL, 2002, p. 3).

No âmbito educacional brasileiro, as práticas pedagógicas inovadoras, associadas às tecnologias, constituem-se como "[...] estratégias para atingir os fins educacionais desejados [...]" (MEC, 2017, p. 2), previstas no Plano Nacional de Educação (PNE) 2014-2024, por exemplo. Assim, pode-se pensar que, "[...] a escola não tem mais que educar, que instruir, formar 
Por uma atenção do cuidado de si na escola em tempos de dispersão hiperconectada

o pensamento justo, mas que ela deve aprender a coletar, selecionar, tratar, memorizar 'informações'" (LAVAL, 2003, p. 221). Dessa forma, o campo educacional afasta-se da e-ducação, no sentido etimológico de conduzir para, como diz Masschelein (2008).

A escola vai, pois, se deslocando em seu sentido pedagógico, sendo tomada como modelo-empresa, onde a aula se torna um grande centro de conexões; a organização curricular dá-se em torno de projetos constituídos por grupos de trabalho formados pelo interesse; a figura do professor esmaece, e ele passa a ser um mediador ou coach. Do mesmo modo, os alunos assumem a responsabilidade pela montagem de seu currículo, bem como por seu sucesso ou fracasso; o ensino cede lugar ao aprender a aprender, como investimento "[...] no próprio capital humano do indivíduo, e os cidadãos-como-aprendizes ativados carregam a responsabilidade vitalícia de encontrar o seu próprio emprego" (MASSCHELEIN; SIMONS, 2014, p. 70).

Conforme a Política de Inovação Educação Conectada (MEC, 2017, p. 3), o Brasil precisa, com urgência, "[...] de diretrizes nacionais que garantam a todos os estados e munícipios condições de implementar ações de inovação e uso de tecnologia nas escolas. Porque a tecnologia já se revelou

14 um instrumento eficaz [... "]" no que diz respeito à igualdade de acesso à educação, à aprendizagem e ao aperfeiçoamento na gestão das redes de ensino. As ferramentas tecnológicas devem, pois, "[...] imprimir eficácia aos processos administrativos, otimizando os recursos públicos de todas as instâncias de poder" (MEC, 2017, p. 3).

Pode-se perceber, assim, que a inovação - e, especificamente, a inovação tecnológica - volta-se para a resolução de problemas, e não à criação de novos problemas. É desse tipo de atenção fragmentada e rápida que aqui se trata. Por isso, a partir de Deleuze, poderíamos pensar que a inovação, nessa perspectiva, seria a outra do pensamento. Cabe-nos perguntar que tipo de atenção poderíamos ainda pensar para resistir a essa discursividade que opera na defesa do interesse individual, do utilitarismo, da aceleração, sendo encontrada em diversas produções acadêmicas e midiáticas que corroem e destroem a atenção como possibilidade de criação de outros modos de pensamento e existência, que não pode se dar sem a conversação no coletivo, com a tradição e com postura de problematização do que estamos nos tornando no presente. 
$\bigcirc$ afã novidadeiro das práticas pedagógicas não tradicionais passa, assim, a mascarar uma esquiva narrativa sem precedentes na história da escolarização; afã embalado pelo mantra da renovação dos negócios deste mundo e, mutatis mutandis, de desprezo absoluto para com ele, já que seus porta-vozes se mostram inapetentes para instaurar conexões vigorosas entre os mortos das obras e os vivos das aulas (AQUINO, 2017, p. 286).

\section{Combate ético e político: por uma atenção do cuidado de si}

Conforme apontado, o conceito da atenção vem sofrendo mudanças significativas. E a maneira como os modos de subjetivação vão se constituindo está relacionada também à forma como a atenção ocupa tais contextos, ou seja, podemos falar em um governo da atenção e, especificamente, de um governo da atenção na escola.

Também apontamos que, especialmente a partir do advento da Internet, operamos, em velocidade frenética, com um grande volume de informações, contribuindo para a desatenção. E aqui não se trata da demonização das tecnologias da informação. Mas também não se trata de um elogio romântico. O que poderia ter sido um momento ímpar na história de acesso a textos, a imagens e a uma longa tradição acumulada vem sendo utilizado com as marcas da supervelocidade, com foco na opinião e na reprodução. Nas instituições escolares, a falta de atenção dos estudantes, bem como o crescente número de crianças e jovens diagnosticados com TDAH, explicitam-se nos discursos docentes, em que (des)interesse, (não) aprendizagem e (in)disciplina são matérias centrais. Porém, as próprias práticas pedagógicas contribuem para essa dispersão quando se chega a realizar, por exemplo, mais de dez exercícios de leitura e de escrita em um turno.

Procuramos, neste texto, trazer a atenção para o centro do debate educacional, deslocada dos déficits, transtornos e problemas de aprendizagem e comportamento, para auxiliar a compreender as relações que se estabelecem no âmbito escolar contemporâneo a partir de outras perspectivas. Tomar por outras perspectivas pode significar problematizar os modos de governo nesta sociedade de controle (DELEUZE, 2008), que opera com características como superprodução e desempenho; onde se compete consigo mesmo para bater suas próprias metas; onde a leitura e a escrita na escola servem para navegar 
Por uma atenção do cuidado de si na escola em tempos de dispersão hiperconectada

e conectar informações; em que eficiência é sinônimo de rapidez e reprodução de conhecimento útil; onde a inovação se coloca como resposta a uma escola que estaria obsoleta por não mais atrair a atenção das crianças e adolescentes do século XXI.

A partir desse diagnóstico que nos mostra a atenção operada como falta e como valor de mercado, optamos por ir pela contramão desse discurso e fazer, justamente, outras perguntas. Decidimos perguntar como essa falta de atenção dos alunos nas aulas, como seu desinteresse pela escola, como essa dificuldade dos professores em reter a atenção dos alunos nas atividades que não são satisfazem diretamente seus interesses e são prazerosas, como esse aumento de crianças com déficit de atenção podem ser tomados como sintomas de uma sociedade que busca tanto por uma utilidade pragmática, um eficiente uso produtivo do tempo e felicidade, e que tem produzido tantos colapsos humanos.

A partir disso, elegemos, não como busca por aplicabilidade ou romantismo nostálgico, o conceito de conversão da Antiguidade greco-romana para tomarmos a necessidade de outra atenção no presente: atenção como conversação na perspectiva do cuidado de si (FOUCAULT, 2014). Um cuidado que convida a "[...] colocar-se à prova, e, esse colocar-se à prova implica uma relação com o presente, um cuidado e atenção, que é ao mesmo tempo, uma relação paradoxal com o nosso tempo" (GONÇALVES, 2019, p. 8). O que se objetiva é a estetização da própria existência, o que passa sempre pela relação com o outro. E não poderíamos justamente advogar por esse argumento da escola como um espaço e um tempo de suspensão (MASSCHELEIN; SIMONS, 2014) para buscarmos exercer outro tipo de atenção para conosco, com os demais e o mundo? Um lugar onde teríamos esse tempo para perder lentendemos para ganharl em certa contemplação e problematização do mundo, o que exige ruminação, diminuição da velocidade, diminuição na agitação do pensamento que produz desatenção?

Dizia Foucault (2014), a partir de Sêneca, que o grande perigo para o pensamento seria justamente a stultitia, ou seja, essa agitação do pensamento que nada consegue reter, lembrar, guardar, que deixa a vida correr sem tomá-la para discussão, o que nos faz pensar muito sobre essa desatenção para consigo e para com o mundo produzida por esta sociedade do desempenho. Necessita-se de alguém e de práticas que nos puxem para fora - e não poderia ser essa a grande brecha na escola, o que exigiria uma outra relação 
entre professores e alunos, uma outra relação com o tempo? Isso porque essa ruminação do ócio cultivado exigiria não a transmissão de um saber para se suprir uma suposta ignorância, mas exercitar-se na atenção para consigo e com o mundo, equipando-se para lidar com a vida, buscando diminuir ao máximo a escravidão dos outros e a escravidão que exercemos sobre nós mesmos. E isso não passaria, no presente, por uma outra relação com o tempo, com os saberes que consideramos importantes na escola (para Sêneca seriam aqueles que transformam a existência) e com os tipos de exercícios de estabelecemos para pensarmos o nosso presente? Quando falamos da atenção como déficit em termos de eficiência ou como um valor de mercado, o quanto podemos nos distanciar para tomá-la como potência para certa formação ética, política e intelectual dos alunos?

Por isso, tratar-se-iam de exercícios de conversação do olhar para, em brechas, suspendermos essa linguagem instrumental que se pretende neutra (em tempos de Escola sem Partido) e que encharca as escolas brasileiras no presente, para ficarmos tão atentos quanto possível ao que se passa conosco e com o mundo. Uma tentativa de equiparmo-nos para fazermos lidação com este mundo de forma menos ingênua, menos violenta e menos opiniática, problematizando o elogio ao absurdo que vivemos no Brasil no presente. Trata-se, então, de concentrar o pensamento na própria ação, o que não significa autodecifração, tal como nas avaliações em larga escala, nem encerramento do sujeito em campos de conhecimento, mas estar frente a frente consigo mesmo para conseguir deslocar-se de si.

Não se trata da conversão cristã em que negamos a nós mesmos em nome de purificação ou de valores superiores, mas uma conversão do olhar que busca atentamente perguntar como fazer para vivermos como se deve. Também não se trata de uma conversão que poderíamos chamar de performática no presente que pretende confirmar o que se é na cultura do espetáculo. Por isso Sêneca falava da conversão como esses exercícios voltados para a constituição de si mesmo, para a constituição de um corpo que passava por um tipo de crítica dos modos de vida, almejando uma bela existência. E essa conversação exige um desvio da agitação cotidiana, da tagarelice, tida como uma grande inimiga, porque seria a outra do pensamento. É esse tipo de atenção que, talvez, poderia ter feitos éticos, estéticos e políticos importantes na formação das pessoas. Todavia, essa conversão a si não diz respeito a um gesto egoísta, pelo contrário, passaria sempre pela relação com o outro, com 
Por uma atenção do cuidado de si na escola em tempos de dispersão hiperconectada

um mestre, daí a sua potência como força política. E essa ocupação consigo mesmo não diz respeito a uma preparação para uma profissão, para certas habilidades e competências, mas sim a um modo de vida (FOUCAULT, 2014).

Entendemos que essa defesa fala, pois, da importância de experimentarmos enquanto escola também um tipo específico de atenção, a partir dessa noção de conversão, mas pensada no presente. Uma abertura a essa relação com o mundo como esse abismo infinito. Por isso, não se trataria de treinar habilidades e competências para focarmos nossa atenção em termos de rentabilidade, mas compartilhar experiências como quem cria problemas. A escola, pois, como essa potência de transmissão de um modo de atenção, uma postura de abertura para consigo e para com os demais.

Por isso falamos em brechas que poderiam funcionar como um combate político que atravessa os modos como ensinamos, como aprendemos, como nos relacionamos conosco e com os demais e como entendemos o lugar da escola no presente. Talvez um dos grandes sistemas de endividamento que vivemos no presente é esse endividamento-desempenho-prazer, que destrói possibilidades de uma relação mais ética consigo e com os demais - porque a atenção está muito fragmentada e acelerada -, procurando conectar informa-

18 ções úteis para investir em si mesmo como capital humano.

Se os alunos estão demasiadamente ocupados com um volume extenso de informações em um tempo agora considerado curto demais, podemos perguntar, a partir da perspectiva foucaultiana do cuidado de si, que sintoma é esse em que, em uma instituição como a escola, os alunos não têm tempo para tomarem a si mesmos e ao mundo como objeto de problematização. $\bigcirc$ que sobra à vida, se ela própria não é tratada como matéria, senão quando na prevenção de doenças, cuidados com alimentação saudável, higiene corporal e exercícios para manter a boa forma? Quando a vida na aula é tomada somente pelo seu aspecto biológico, enfatizando uma vida nua? Ao mesmo tempo, colocamos uma miríade de conteúdos, alguns assumindo o status de disciplina em escolas do presente, voltados à praticidade da própria vida nua, como Educação Empreendedora, por exemplo. Deixamos de valorar o importante para valorar o útil? Perguntaria Nietzsche: útil para quê? Para quem?

Por isso, fazemos um combate da atenção que se desloca das competências para a formação, como uma ética da atenção que não opera de forma transcendente, mas se faz na artesania de estar consigo e com o outro nesse 
espaço público e coletivo que pode ser a escola. Em tempos de uma dispersão hiperconectada, como poderíamos pensar o exercício de pensamento junto ao professor, aos colegas, à comunidade, para tomar a escola, a sala de aula, como o lugar-comum de encontro entre o velho e o novo, entre os mortos e os vivos, pensada em sua potência criadora e renovadora de mundo? Como essa pequena, mas importante conversão do olhar, poderia ser percebida como uma possibilidade, e não como um entrave e uma perda de tempo? Agora, para isso, precisamos de certo tempo de ruminação para inventarmos outros problemas, para sermos capazes de pensar e viver de outros modos. Para sermos capazes de viver e não apenas sobreviver, para sermos capazes de pensar, não apenas opinar.

\section{Notas}

1 Ao pesquisar atenção em Periódicos SciELO, encontramos 2.377 trabalhos. Utilizando os filtrosBase de dados: article/Pesquisa: atenção [Palavras do título], obtivemos 251 textos. Destes, apenas 26\% não estavam relacionados a algum problema ou síndrome. Dos 52 trabalhos selecionados para análise, $67 \%$ foram publicados em periódicos das Neurociências. Somente 15\% pertenciam à área da Educação.

\section{Referências}

AGOSTINHO. A cidade de Deus. Tradução João Dias Pereira. Lisboa: Fundação Calouste Gulbenkian, 2000.

AQUINO, Julio Groppa. Defender a escola das pedagogias contemporâneas. ETD-Educação Temática Digital, Campinas, v. 19, n. 4, p. 669-690, out./dez. 2017.

ARISTÓTELES. Ética a Nicômaco. Poética. Tradução Leonel Vallandro e Gerd Bornheim. São Paulo: Nova Cultural, 1991.

BALL, Stephen. Reformar escolas/reformar professores e os terrores da performatividade.

Revisła Portuguesa de Educação, Braga, v. 15, n. 2, p. 3-23, 2002.

CALIMAN, Luciana Vieira. A biologia moral da atenção: A Constituição do Sujeito (Des) Atento. 2006. 274 f. (Tese de Doutorado) - Programa de Pós-Graduação em Saúde Coletiva, Universidade do Estado do Rio de Janeiro, 2006.

CALIMAN, Luciana Vieira. Os valores da atenção e a atenção como valor. Estudos e Pesquisas em Psicologia, Rio de Janeiro, v. 8, n. 3, p. 632-645, set./dez. 2008. 
CALIMAN, Luciana Vieira. Os regimes da atenção na subjetividade contemporânea. Arquivos Brasileiros de Psicologia, Rio de Janeiro, v. 64, n. 1, p. 2-17, abr. 2012.

COSTA, Sylvio de Sousa Gadelha. Governamentalidade neoliberal, teoria do capital humano e empreendedorismo. Educação \& Realidade, Porto Alegre, v. 34, n. 2, p. 171186, maio/ago. 2009.

CRARY, Jonathan. Suspensões da percepção: atenção, espetáculo e cultura moderna. Tradução Tina Montenegro. São Paulo: Cosac Naify, 2013.

DARDOT, Pierre; LAVAL, Christian. A nova razão do mundo: ensaio sobre a sociedade neoliberal. Tradução Mariana Echalar. São Paulo: Boitempo, 2016.

DELEUZE, Gilles. Conversações. 1972-1990. Tradução Peter PálPelbart. Rio de Janeiro: Editora 34, 2008.

DE-NARDIN, Maria Helena; SORDI, Regina Orgler. Um estudo sobre as formas de atenção na sala de aula e suas implicações para a aprendizagem. Psicologia \& Sociedade, Porto Alegre, v. 19, n. 1, p. 99-106, abr. 2007.

DESCHAMPS, Eduardo; CALEGARI, Diego. Introdução. In. EHLERS, Ana Cristina da Silva Tavares; TEIXEIRA, Clarissa Stefani; SOUZA, Marcio Veira de. Educação fora da caixa: tendência para a educação no século XXI. Florianópolis, SC, Bookess, 2015.

EHRENBERG, Alain. O sujeito cerebral. Psicologia Clínica, Rio de Janeiro, v. 21 , n. 1, p. 187-2 13, 2009 (Tradução Marianna Oliveira e MonahWinograd).

FOUCAULT, Michel. Vigiar e punir: nascimento da prisão. Tradução Raquel Ramalhete Petrópolis: Vozes, 2004.

FOUCAULT, Michel. Em defesa da sociedade. Tradução Maria Ermantina Galvão. São Paulo: Martins Fontes, 2005.

FOUCAULT, Michel. Arqueologia do saber. Tradução Luiz Felipe Baeta Neves. Rio de Janeiro: Forense Universitária, 2008.

FOUCAULT, Michel. A hermenêutica do sujeito: curso dado no Collège de France 11981 1982). Tradução Márcio Alves da Fonseca. São Paulo: Martins Fontes, 2014.

Foucault, Michel. Microfísica do poder. Tradução Roberto Machado. Rio de Janeiro: Paz e Terra, 2017.

FRANCK, Georg. The scientific economy of attention: a novel approach to the collective rationality of Science. Scientometrics, v. 55, n. 1, p. 3-26, sep. 2002. 
GALLO, Sílvio. Deleuze \& a educação. Belo Horizonte: Autêntica, 2008.

GONÇALVES, Teresa Nico Rego. Pesquisa|-|formação: composições a partir de experiências de leitura e escrita na universidade. Revista Educação em Questão, Natal, v. 57, n. 53, p. 1-23, jul./set. 2019.

HAN, Byung-Chul. Sociedade do cansaço. Tradução Enio Paulo Giachini. Petrópolis: Vozes, 2017.

HATFIELD, Gary. Attention in early scientific psychology. In: WRIGHT, Richard D. (Ed.). Visual attention. New York, NY, US: Oxford University Press, 1998.

JAEGER, Werner. Paideia: a formação do homem grego. Tradução Artur M. Parreira. São Paulo: Martins Fontes, 1994.

KASTRUP, Virgínia. A aprendizagem da atenção na cognição inventiva. Psicologia \& Sociedade, Porto Alegre, v. 16, n. 3, p. 7-16, set./dez. 2004.

LAVAL, Christian. A escola não é uma empresa: o neo-liberalismo em ataque ao ensino público. Tradução Maria Luiza de Carvalho e Sila. Londrina: Editora Planta, 2003.

MACHADO, Roberto. Foucault, a ciência e o saber. Rio de Janeiro: Jorge Zahar, 2006.

MASSCHELEIN, Jan. E-ducando o olhar: a necessidade de uma pedagogia pobre. Educação \& Realidade, Porto Alegre, v. 33, n. 1, p. 35-48, jan./jun. 2008 (Tradução Lisa Becker).

MASSCHELEIN, Jan; SIMONS, Maarten. Em defesa da escola: uma questão pública. Tradução Cristina Antunes. Belo Horizonte: Autêntica Editora, 2014.

MINISTÉRIO DA EDUCAÇÃO. Política de inovação educação conectada. Brasília: Secretaria de Regulação e Supervisão da Educação Superior (SERES), 2017. Disponível em: http:// portal.mec.gov. br/secretaria-de-regulacao-e-supervisao-da-educacao-superior-seres/30000-uncategorised/57671-plataforma-integrada. Acesso em: 15 nov. 2019.

Ó, Jorge Ramos do. O governo de si mesmo: modernidade pedagógica e encenações disciplinares do aluno liceal (último quartel do século XIX - meados do século XX). Lisboa: Educa e Autor, 2003.

Ó, Jorge Manuel Ramos do. A governamentalidade e a história da escola moderna: outras conexões investigativas. Educação \& Realidade, Porto Alegre, v. 34, n. 2, p. 97-117, maio/ago. 2009.

OCDE. Manual de Oslo. Diretrizes para coleta e interpretação de dados sobre inovação. Brasilia: Finep, 2005. 
ORTEGA, Francisco. O corpo transparente: visualização médica e cultura popular no século XX. História, Ciências, Saúde-Manguinhos, Rio de Janeiro, v. 13, p. 89-107, out. 2006 (suplemento).

PETERSON, Amelia. The purpose of pedagogy. In:PETERSON, Amelia; DUMONT, Hanna; LEFUENTE, Marc; LAW, Nancy. Understanding innovative pedagogies: Key themes to analyse new approaches to teaching and learning. OECD Education Working Papers. Paris: OECD Publishing, 2018 (n. 172).

SENNETT, Richard. A cultura do novo capitalismo. Tradução Clóvis Marques. Rio de Janeiro: Record, 2015.

SIBILIA, Paula. O show do eu: a intimidade como espetáculo. Rio de Janeiro: Nova Fronteira, 2008.

SIBILIA, Paula. Redes ou paredes: a escola em tempos de dispersão. Rio de Janeiro: Contraponto, 2012.

SILVA, Divino José; Vaz, Alexandre Fernandez. A emergência do sujeito cerebral e suas implicações para a Educação. Childhood \& Philosophy, Rio de Janeiro, v. 12, n. 24, p. $211-230$, maio/ago. 2016.

22 VAL, Gisela Maria do; AQUINO, Julio Groppa. A ordem do discurso jornalístico sobre educação: uma análise das matérias da Folha de S. Paulo de 1996 a 2006. Educação em Revista, Belo Horizonte, v. 29, n. 1, p. 93-120, mar. 2013.

ZORZANELLI, Rafaela; ORTEGA, Francisco. Cultura somática, neurociências e subjetividade contemporânea. Psicologia \& Sociedade, Florianópolis, v. 23, p. 30-36, 2011 (número especial). 
Doutoranda Maria Alice Gouvêa Campesato

Programa de Pós-Graduação em Educação Universidade do Vale do Rio dos Sinos (São Leopoldo - Brasil) Integrante da Equipe Técnico-pedagógica da Secretaria Municipal de Educação de Porto Alegre

Práticas curriculares de escrita e leitura nos Anos Iniciais do Ensino Fundamental e os modos de subjetivação ORCIDID: https:/ / orcid.org/0000-0002-1965-9564

E-mail: mcampesato@yahoo.com.br

Profa. Dra. Betina Schuler Universidade do Vale do Rio dos Sinos (São Leopoldo - Brasil) Programa de Pós-Graduação em Educação

Práticas Curriculares de Escrita e Leitura nos Anos Iniciais do Ensino Fundamental e os Modos de subjetivação ORCIDID: http: / / orcid.org/0000-0002-2424-760 1 E-mail: beschuler@unisinos.br/betinaschuler@hotmail.com

Recebido 16 out. 2019 Aceito 13 nov. 2019 